\title{
TAXIONOMIAS SOCIAIS DO MAGISTÉRIO OFICIAL PAULISTA: ESTUDO A PARTIR DE NECROLÓGIOS
}

\author{
GILSON R. DE M. PEREIRA \\ Professor da Faculdade de Educação da Universidade Regional do \\ Rio Grande do Norte - URRN
}

\begin{abstract}
RESUMO
O objetivo da pesquisa, a partir da análise de necrológios de professores - publicados nojornal dos Professores, órgão oficial do Centro do Professorado Paulista - CPP-, durante os anos de 1980 a 1990 -, é apreender as formas de classificação e os critérios de visão e divisão do mundo do professorado paulista, representados nos necrológios por meio dos signos que revelam a qualidade e o valor de uma pessoa, bem como explicitar os mecanismos utilizados para a fixação dos padrões morais do campo encarnados nas figuras desaparecidas. TAXIONOMIASEDUCACIONAIS-PROFESSORES-SÃOPAULO_CENTRODOPROFESSORADOPAULISTA
\end{abstract}

\begin{abstract}
TAXONOMY OFTHEPAULISTA OFFICIAL TEACHING. ASTUDYFROMTHETEACHERSNECROLOGIES. The aim of this research is from the teachers necrologies analyses - published in the Jornal dos Professores, official organ from the Paulistas Teaching Centre, from 1980 to 1990 - apprehend the ways of classification and the Paulista teaching society as well as its points of view and limits criteria, represented into the necrologies by signs that show the quality and value of a person. It also clarifies the mechanism used to fix the moral pattern from this field, embodied in the disappeared people.
\end{abstract}


A análise de necrológios de professores permite apreender os esquemas de percepção e apreciação que os agentes do magistério acionam para perceber e valorizar a si mesmos e aos outros. Constituindo um expediente bastante eficaz de imposição dos interesses mais "desinteressados" ("amor à causa educativa", "alto espírito público", "verdadeiro sacerdócio", "dedicação", "idealismo"), os necrológios são, juntamente com os discursos de paraninfos, as avaliações em bancas de concurso para provimento de cargos no campo educacional, as biografias dos educadores ilustres, as fichas de avaliação escolar etc., lugares privilegiados para a análise das estratégias de sagração e consagração por meio das quais são fixados e difundidos os valores e os modelos partilhados pelo professor comum.

A análise realizada nesta pesquisa cobriu todos os 78 necrológios de 83 números do Jornal dos Professores, isto é, do n. 166 , de fevereiro de 1980 ao n.249, de novembro de 1990'. Desse total, 62 são necrológios de homens e 16, de mulheres. Apenas 3 necrológios tinham autoria definida. Ocasionalmente os necrológios eram publicados na coluna "Atividades no interior - nossas sedes regionais", o que leva a supor que foram redigidos nas sedes do interior e enviados ao Jornal, na capital. A autoria dos demais necrológios provavelmente deve ser atribuída aos assistentes de redação do Jornal.

No Jorna/ não havia lugar definido para os necrológios: podiam aparecer já na segunda página, raramente na primeira, e até na última. Distinguiam-se das notas de falecimento, simples registros de óbito que, provavelmente, seguiam o hábito da imprensa comum segundo o qual os familiares do falecido enviam nota ao jornal, que a publica. No início dos necrológios, em geral constavam a foto do falecido, uma chamada destacada em negrito - "Faleceu o professor Fulano" - e os dados biográficos sumários, ou seja, local e data de nascimento, filiação. Na seqüência, apareciam os nomes dos enlutados, geralmente esposa e filhos, descrição da carreira, que podia ser mais ou menos extensa, e, finalmente, uma avaliação na forma de adjetivos que davam idéia da dimensão da perda para o magistério. Essa fórmula, quase sempre a mesma, já permite apreender o seguinte: além de um esquema de neutralização da morte, a reiteração da fórmula sugere um processo didático de fixação de valores. Além de uma racionalização da morte, aceitação do inelutável, os necrológios constituem aulas de "como ser", sobre os modos de "agir reto e correto", uma explanação singela do que valorizar e do que incorporar, do que, enfim, interessa aos membros do magistério, segundo o Jornal.

Os necrológios, acionados pela inevitável carga emotiva que os acompanha, emotividade esta, por sua vez, controlada pelas formas protocolares de elogio aos mortos, expressam a representação que o professor faz de si mesmo e de sua profissão. Ou seja, por meio de formas eufemizadas, complacências rituais e avaliações morais inteiramente voltadas à consagração dos agentes, transfigurações de vidas, em geral comuns, em vultos

I. Este estudo expõe os primeiros resultados de pesquisa que o autor vem desenvolvendo sob orientação do professor Nilson José Machado, da Faculdade de Educação da USP. 
de uma densidade quase impalpável, os necrológios explicitam e disseminam os critérios da excelência moral, social e profissional dos membros do magistério oficial paulista. Os necrológios constituem uma hagiografia cuja eficácia simbólica repousa na cegueira fetichista produzida por todos os expedientes de idealização das vidas ("de sentimentos cristãos e acendrado civismo", "desempenho exemplar de suas funções docentes", "maneira perseverante e sempre construtiva"), hagiografia esta, por sua vez, comandada diretamente pelo maior ou menor patrimônio educacional (e também político) deixado pelo morto.

\section{FORMAS DE CLASSIFICAÇÃO DO MAGISTÉRIO}

Nos necrológios, os graus de consagração correspondem às trajetórias e posições ocupadas pelos agentes no magistério, ou seja, aos postos mais ou menos elevados no interior das hierarquias profissionais, que também correspondem a maior ou menor ambição profissional, a maior ou menor resignação etc., tudo isso mediado pela origem social, quer dizer, pela trajetória da família do morto e pelo acúmulo de capital prévio, cultural e de relações sociais, dos agentes. Por essa lógica, uma carreira profissional discreta é identificada a adjetivos formalmente neutros, que geralmente remetem às características privadas do morto (bom, amigo, amável). Carreiras discretas são também qualificadas por expressões e adjetivos que denotam esforço, tais como "cumpridor exemplar dos seus deveres", "perseverante" e "operoso", condição decerto indispensável para a superação das inúmeras limitações a que estão sujeitos os agentes de origens sociais desfavorecidas, mas que expõem os signos de reconhecimento por meio dos quais é revelada a baixa rentabilidade material e simbólica das posições ocupadas. Às melhores carreiras são reservadas expressões tais como "alto espírito público", "capacidade inconteste" etc., que sugerem o poder de mando, a liderança e as competências sobretudo políticas dos finados. Os termos que revelam mais claramente interesse no "desinteresse" (civismo, idealismo, sacerdócio, sentimentos cristãos, espírito público) estão de certo modo presentes em todas as carreiras, sugerindo uma espécie de valor supremo partilhado igualmente por todos, uma moeda comum, uma marca do campo que a todos identifica, um preço que todos devem pagar independentemente do sucesso ou do insucesso, dos postos acumulados ou dos prêmios recebidos. A rigorosa parcimônia, para não dizer a quase ausência, de adjetivos reservados às mulheres, ao lado de trajetórias femininas em geral medíocres, provavelmente obstaculizadas por relações de poder assimétricas entre os gêneros, confirma que, pelo menos no período analisado, o magistério constituía trabalho para as mulheres e carreira para os homens.

\section{ALGUNS NECROLÓGIOS EXEMPLARES}

Nos quadros I e 2 a seguir reproduzem-se alguns necrológios resumidos, agrupa- 
dos segundo as posições ocupadas pelos falecidos. Em cada resumo consta a localização do necrológio, isto é, número e data do Jornal dos Professores, a carreira do falecido, ou seja, os postos ocupados e os locais de atuação, e as expressões e os adjetivos empregados para homenageá-lo e, principalmente, qualificá-lo.

Talvez seja o caso de reiterar aqui que as clivagens profissionais e as hierarquias de competência, traduzidas nos necrológios por meio da descrição das trajetórias desenvolvidas e das posições conquistadas no campo, quer dizer, por meio do capital simbólico acumulado pelo falecido, comandam diretamente a avaliação post-mortem que dele se faz e, por conseguinte, orientam a lógica da distribuição, nos necrológios, das qualidades pessoais e dos predicados de espírito atribuídos aos agentes.

\section{VIRTUDES MISSIONÁRIAS E DESINTERESSE}

Não é incomum que os necrológios de agentes que percorreram trajetórias discretas revelem - mais nitidamente do que os dos demais - virtudes missionárias e disposições para o trabalho comunitário. Visto que grande parte desses agentes exerceram a profissão em pequenas cidades do interior do estado, a atuação religiosa e comunitária provavelmente aparece como um mecanismo extra de rentabilizar, pela ampliação do capital de relações sociais, tanto a profissão quanto a posição ocupada pelo agente no magistério. Nesses casos comparecem expressões tais como "de princípios religiosos profundos e autênticos", "de sentimentos cristãos e acendrado civismo", "atividade altamente profícua", "decisiva e desinteressada colaboração", "cidadão prestante". No necrológio de E. M., professor que atuou em Ipeúna, Paraíso e Rio Claro, o falecido é descrito a partir dessa perspectiva: "Vicentino atuante, dedicado às obras sociais. Participante de cursos de noivos em paróquia da comunidade local, foi o professor E. M. um exemplo de mestre, de educador, de colega e de amigo" (JP, n. 194, ago. 1983, p. 2). As atividades comunitárias de um outro agente que também percorreu carreira modesta, realçadas como "fecundas", são descritas do modo a seguir, complementadas pela observação quanto à colaboração na imprensa, valor muito comum nos necrológios, recurso geralmente utilizado para designar participação atuante:

Além de suas atividades profissionais e dos serviços prestados à associação de classe, deu ainda sua colaboração a várias atividades cívicas e sociais, como fundador de clube de serviços, membro do júri, colaboração em jornais e diversas atividades comunitárias. (Necrológio de J. A. C., JP, n. 231, ago. 1988, p. 2)

Quase os mesmos ingredientes fazem-se igualmente presentes no necrológio desse outro agente que, embora tenha percorrido carreira discreta no magistério, chegou a diversas assessorias na Assembléia Legislativa, na Secretaria de Educação do Estado e na Prefeitura de São Caetano do Sul: "Com grande atuação em sua área e também na 
QUADRO I

NECROLÓGIOS EXEMPLARES

MELHORES CARREIRAS NO MAGISTÉRIO

\begin{tabular}{|c|c|c|}
\hline NOME & CARREIRA & QUALIFICAÇÕES \\
\hline R. S. F. & $\begin{array}{l}\text { pertenceu à Academia Brasileira de Litera- } \\
\text { tura Infantil e Juvenil, à Academia Paulista de } \\
\text { Educação, vencedor do Prêmio Jabuti e da } \\
\text { Placa de Prata, ambos da Câmara Brasileira } \\
\text { do Livro, membro do Instituto de Ciências e } \\
\text { Letras de São Paulo e da Associação Brasilei- } \\
\text { ra de Museologia. Autor de livros didáticos, } \\
\text { diretor de vários grupos escolares de cida- } \\
\text { des do interior, formado na Escola Normal } \\
\text { da Praça da República. }\end{array}$ & $\begin{array}{l}\text { ilustre, grande, lembrança } \\
\text { imorredoura, dotado de exce- } \\
\text { lentes predicados, ardoroso pa- } \\
\text { ladino da velha escola normal, } \\
\text { empolgante ( JP, n. I67, mar. } \\
\text { I980, p. 4). }\end{array}$ \\
\hline L. C. & $\begin{array}{l}\text { professor, delegado, inspetor escolar e di- } \\
\text { retor de escola no interior e na capital, dire- } \\
\text { tor de uma delegacia de ensino. Assistente } \\
\text { do Diretor Geral da Educação do Estado, } \\
\text { assistente da Secretaria de Educação da pre- } \\
\text { feitura de São Paulo, Diretor do Material da } \\
\text { Secretaria da Educação do Estado, presidente } \\
\text { do CPP (1948-49). }\end{array}$ & $\begin{array}{l}50 \text { anos prestados à causa pú- } \\
\text { blica, idealismo, alto espírito } \\
\text { público, capacidade inconteste, } \\
\text { beletrista de apurado gosto e } \\
\text { requintada forma ( JP, n. I8I, } \\
\text { set. } \mid 98 \text { I, p. 8). }\end{array}$ \\
\hline O. R. & $\begin{array}{l}\text { professor, diretor de escola, inspetor esco- } \\
\text { lar, delegado de ensino, assistente geral e } \\
\text { oficial de gabinete do diretor geral do De- } \\
\text { partamento de Educação. Cidadão honorá- } \\
\text { rio de Osasco e Cajamar, laureado com as } \\
\text { medalhas "Couto de Magalhães", "José } \\
\text { Bonifácio" e "Anchieta". Membro do Conse- } \\
\text { Iho Superior do CPP. }\end{array}$ & $\begin{array}{l}\text { entusiasta, idealista, símbolo das } \\
\text { virtudes da classe, veemente, } \\
\text { devotado, líder infatigável ( } P \text {, } \\
\text { n. } 202 \text {, set. } 1984, \text { p. I). }\end{array}$ \\
\hline
\end{tabular}




\section{QUADRO 2}

\section{NECROLÓGIOS EXEMPLARES}

\section{CARREIRAS DISCRETAS}

NOME

\section{CARREIRA}

\section{QUALIFICAÇÕES}

L. L. S.

delegado de ensino, diretor de escola e ins-

profundamente honesto, bom, petor em várias cidades do interior e da cahumano, de sentimentos crispital, membro do Conselho Superior do CPP. tãos e acendrado civismo ( $/ P, \mathrm{n}$. I7I, ago. 1980, p. 7).

Z. G. R. A.

lecionou no ensino público durante 32 anos professora emérita, vocacionaem grupo escolar no Belém, na capital. da para o magistério (JP, n. I74, nov. 1980, p. 4).

professor, supervisor e diretor de escolas do interior (Campinas, Promissão, Buritama, llha de S. Sebastião, Valparaíso).

simples, amável, sincero, culto, dinâmico, bondoso e cumpridor exemplar dos seus deveres ( $J P$, n. 175, fev. 198I, p. 5).

W. M. B. delegado de ensino da região escolar de Bauru, membro do Conselho Superior do benquisto, atuante $(J P, \mathrm{n} .176$, mar. 1981, p. 5).

CPP.

S. R. N.

membro do Conselho Superior do CPP, personalidade suave e tranqüiprofessor e diretor de escolas no interior (Balbinos, Valparaíso, Ribeirão do Vale). la, mestre operoso, administrador capaz (JP, n. 177, abr. 198I, p. 8).

T. M. A. professor e diretor de escola, no interior e 50 anos de magistério, de senna capital, delegado regional de ensino, membro das Congregações Marianas, cidadão honorário de Fernandópolis e Cosmorama, timentos cristãos e acendrado civismo (JP, n. I80, ago. I98I, p. 3). vereador na capital. 
comunidade em inúmeras comissões organizadoras de eventos de elevado alcance social, foi cidadão prestante" (necrológio de M. F., JP, n. 219, set./out. 1986, p. 2).

O necrológio de O. S., professor radicado em Santa Cruz do Rio Pardo, escrito por colegas seus e publicado na seção "Os professores escrevem", é particularmente interessante por trazer à luz, no detalhe, o modelo de professor considerado de bons predicados. Observar a descrição do falecido como indivíduo resignado e jovial, o que constitui valor no magistério, sobretudo para os agentes estruturalmente não autorizados a ter ambições. A trajetória seguida e a posição ocupada, bem como o reconhecimento e a adesão a práticas culturais cuja relação e nomeação são tanto mais justificáveis quanto mais canônicas (isto é, escolares).

...anos e anos a fio, habituamo-nos a vê-lo e a ouvi-lo, enfim, a conhecer melhor o seu grande coração, sem maldade e sem ambições. (...) Sempre alegre e disposto, dedicado aos amigos, à boa leitura, ao teatro, à música, à poesia e a escrever (...) bom colega, bom amigo, bom esposo e pai de família e, acima de tudo, profundamente cristão e humano. (JP, n.203, out. 1984, p. 7)

Muito presente nos necrológios, os termos que sugerem o interesse no "desinteresse", tais como idealismo e sacerdócio, aparecem periodicamente associados, especialmente nas carreiras menores, à grandiosidade da "missão" docente e ao "santuário" que, como tal, é considerada a escola. Assim, o extrato do necrológio a seguir é exemplar nessa modalidade de consagração: "dedicou sua vida ao ideal sublime de educar crianças (...) homenagem a um homem idealista que doou sua vida a uma profissão grandiosa - Professor. (...) P. M., hoje perto do Pai, ajude-nos na difícil e grandiosa missão de educar" (JP, n. 219 , set./out. 1986, p. 2). Outra carreira, a de um agente que galgou postos elevados no magistério e acumulou honrarias, também é descrita sob a mesma clave do idealismosacerdócio:

Idealista ao extremo e dotado daquelas qualidades morais, cívicas e intelectuais que ornamentam a personalidade do autêntico educador (...) Era aquela sua condição de idealista que lembramos a pouco, a grande responsável pelos sentimentos que expressava (...) Um longo apostolado educacional coroou a vida de A. A. (JP, n. 24I, out./nov. 1989, p. 8)

É proveitoso citar trechos de uma espécie de carta-testamento: trata-se de carta escrita pelo professor J. M. F., de São José do Rio Pardo, que viria a falecer pouco tempo depois do envio do texto aos seus filhos, publicada no Jornal dos Professores sob o título "Aos filhos que ficaram". Produto das tensões e angústias de quem se vê às vésperas da morte, vítima de mal incurável, o texto é interessante por trazer à luz valores e disposições do magistério paulista à época. Muito possivelmente agente de carreira humilde, o autor utiliza-se de "metáforas da jardinagem" para referir-se ao trabalho docente, metáforas decerto destinadas a enobrecer a profissão, mas que, afi- 
nal, expõem disposições humildes e demissionárias, além de exortar os filhos à resignação, à fé, ao modelo cristão de virtude e à força necessária para superar as inúmeras dificuldades e coações estruturais decorrentes das posições ocupadas por ele e sua família, disposições que constituem trunfo negativo dos que, como os agentes do magistério, partilham os espaços sociais dominados, quer em relação ao campo do poder, quer em relação à produção simbólica.

Eu sempre gostei de pegar sementes, semeá-las, cuidar, sem ter um pedaço de terra para colocar plantinhas que vão ser grandes árvores. (...) Por isso, vivia semeando. Alguém vai desfrutar, não importa quem. Isso é para esclarecer que devemos fazer o bem sem olhar a quem. (...) Usem dessa grande verdade cristã: só façam o bem. Em casa, na família, com os amigos, com quem vocês vão conviver neste mundo e até mesmo com os inimigos. (...) Meus filhos, não vou lhes deixar fortuna, mas o pouco que deixar servirá para o começo de suas vidas. (...) Juntem as bagagens que já possuem: cultural, moral, religiosa e vão em frente por este mundo que é expressão divina. ( JP, n. 234, dez. 1988, p. 7)

\section{A ORGANIZAÇÃO DO ESPAÇO AXIOLÓGICO}

Pelas carreiras dos agentes é possível estabelecer o quadro III, a seguir, dos valores dominantes - expressos por meio dos adjetivos reservados às melhores carreiras - e dos valores dominados, incorporados nos adjetivos utilizados para qualificar as carreiras dos agentes que ocuparam postos discretos no magistério.

QUADRO 3

DUALIDADE DE VALORES

\begin{tabular}{|cc|}
\hline $\begin{array}{c}\text { Valores dominantes/pólo masculino } \\
\text { ilustre, grande, }\end{array}$ & Valores dominados/pólo feminino \\
elevado espírito público,capacidade inconteste, & bondoso, simples, amável, \\
veemente, devotado, entusiasta & tranqüilo, operoso, cumpridor dos deveres, \\
vocacionado
\end{tabular}

Tudo indica que as taxionomias de valores expostas nos necrológios estão assentadas na oposição que se estabelece entre o conjunto das qualificações que denotam distância respeitosa (grande, líder, capacidade inconteste - pólo dominante no interior do universo dominado do magistério), reservado aos agentes que percorreram as trajetórias mais legítimas e consagradoras e ocuparam os postos mais elevados, e o conjunto das qualificações que expressam familiaridade (bom, amável, amigo - pólo dominado no interior do universo dominado do magistério), reservado aos agentes cujas trajetórias os conduziram a 
postos mais modestos ${ }^{2}$. Todas as avaliações nos necrológios orientam-se a partir desse eixo básico de oposições, que provavelmente é, em última análise, a transfiguração para a esfera axiológica das dicotomias que se estabelecem entre as carreiras masculinas e femininas. As primeiras são socialmente destinadas ao "trabalho de valorizar os produtos das atividades econômicas dominantes", enquanto as carreiras femininas são relegadas ao "trabalho de eufemização da dominação" (Miceli, 1977, p.65). Dicotomias tão mais dramáticas no magistério quanto mais se considera a posição global do campo educacional no espaço de todas as posições sociais, quer dizer, quanto mais se considera a "feminização social" do magistério. Verdadeira mágica que transpõe para a escola todos os signos de distinção associados à gestão feminina do capital doméstico e cujo resultado, por força tanto da alquimia das trocas entre os gêneros quanto das estratégias sociais de distinção entre as famílias e os grupos, é a desvalorização e desqualificação da profissão, tornando por isso mais intensas (e mais sutis) no interior do próprio campo as lutas empreendidas pelos agentes na tentativa de se distinguirem da "contaminação" feminina ${ }^{3}$.

A familiaridade, entendida como modalidade de apreensão das relações sociais sob a forma de trocas afetivas, é a forma possível de manifestação da "libido" profissional para os agentes mais humildes do magistério, sobretudo para as mulheres. Enclausurados num espaço social que os relegou a serem percebidos pelos outros como dignos, nobres, sérios, devotados e idealistas, porém pequenos, formas decerto eufemizadas de desqualificálos, os membros do magistério que ocupavam os postos mais baixos da carreira foram condicionados por todas as transações semi-inconscientes da família, pela ação pedagógica da escola, pelos enunciados eficazes do campo educacional e pelos poderes externos a estimarem-se e a reconhecerem-se na forma convertida de relações carregadas de afetividade. Essa via transversa se configura como o mais provável investimento profissional para esses agentes do magistério e a única forma que lhes restou de capital simbólico, pequeno pecúlio sistematicamente ameaçado, tão ameaçado quanto as "vantagens e regalias" da corporação. Infantilismo, sem dúvida, cujo segredo pode ser descortinado na tríplice dominação a que estavam submetidos os agentes mais dominados do magistério: na posição do magistério relativa ao campo do poder, condenada que está a profissão ao trabalho de eufemização da dominação, na posição ocupada pelo agente no interior do próprio magis-

2. A oposição entre distância respeitosa e familiaridade nas relações interpares dos mestres guarda homologia com a oposição entre distância respeitosa e familiaridade nas relações entre professores e alunos nas situações escolares. A longinquo reverentia, isto é, a distância respeitosa e o respeito através da distância no uso da linguagem em relações escolares, é analisada em Bourdieu e Passeron (1994). A distância respeitosa e a familiaridade, formas que os grupos sociais mantêm de conhecimento e reconhecimento da cultura legítima, são analisadas em Bourdieu e Saint-Martin (1983).

3. Capital doméstico é o capital simbólico das famílias. São as mulheres as encarregadas de gerir esse tipo de capital (cf. Bourdieu, 1995). A tarefa de gestão do capital doméstico incorpora-se nas mulheres na forma de hexiscorporal (graça, beleza, simpatia, amabilidade, elegância, docilidade, paciência etc.) A partir disso, verifica-se que não é de modo algum casual que adjetivos associados a essa modalidade de conformação do corpo sejam usados, nos necrológios, para qualificar os agentes (homens e mulheres) que ocuparam postos discretos no magistério. 
tério e na submissão do feminino nas relações de gênero, forma quase paradigmática de violência simbólica, simultaneamente espontânea e coagida, "efeito durável" da ação da ordem social sobre os agentes (cf. Bourdieu, 1997, p. 204). Isso provavelmente lança luz no fato de os adjetivos que evocam familiaridade substituírem quase inteiramente as referências a saberes e conhecimentos, ou seja, a qualidades e competências estritamente técnicas, quer dizer, propriamente pedagógicas, atribuídos a esses agentes mais humildes, especialmente às mulheres.

Além disso, a anteriormente referida transposição para a escola dos signos de distinção associados à gestão do capital doméstico explicita uma característica oculta dos adjetivos que revelam familiaridade (amigo, estimado, bondoso); ou seja, a recusa do econômico. Princípio de construção da realidade social construído e socializado por todos os agentes colocados em posições homólogas às dos membros mais dominados do magistério (ocupantes dos postos mais desprestigiados de um universo prestigioso). Condicionados, como já se disse, a reconhecerem-se na forma de estima e afeto, acostumados à despossessão dos atributos técnicos da profissão, isto é, da competência propriamente pedagógica, esses agentes carregam para a escola o princípio de construção - a recusa do econômico - constitutivo do habitus que faz da família (e, a fortiori, da profissão) um lugar em que "se suspende o interesse no sentido estrito do termo, isto é, a busca da equivalência nas trocas", ou seja, um "universo onde são suspensas as leis ordinárias do mundo econômico" (Bourdieu, 1993, p.33). Essa ambigüidade, a recusa do econômico em agentes economicamente despossuídos, é adequada às condições sociais de produção das disposições ambíguas, isto é, o que é a mesma coisa, à ambigüidade das posições ocupadas, que, no caso dos membros do magistério, são caracterizadas sobretudo pelo fato de pertencerem a uma corporação de profissionais desprestigiados do prestigioso mundo da produção simbólica.

A distância respeitosa, por sua vez, atribuída aos agentes que galgaram os postos mais elevados da profissão e que chegaram até aos postos de deputado estadual e federal, vereador, secretário de educação, presidente do CPP, assessor de cargos importantes nas hierarquias políticas etc., decorre das estratégias de consagração desses agentes mais bem aquinhoados e que foram capazes de transpor as barreiras produzidas pelas estratégias de relegação impostas ao conjunto dos agentes do magistério. Muito provavelmente dotados dos capitais prévios que faltavam à maioria dos agentes do magistério, ao não se deixarem "contaminar" pelos estereótipos da profissão (resignação, sacerdócio) e pela feminização (eufemização da dominação), conseguiram reconverter suas credenciais propriamente simbólicas em capital político e, por conseguinte, ser cooptados para as carreiras de "homem".

Entre esses dois pólos de atração - distância respeitosa e familiaridade - oscilam as expressões que revelam interesse no "desinteresse" (idealismo, sacerdócio, espírito público), moeda corrente dispersa em todo o campo, como já se disse, mas cujo efeito de consagração varia de acordo com as carreiras, isto é, o termo que evoca o desinteresse é 
tanto mais significativo quanto maior a distância respeitosa sugerida pela carreira do morto. De fato, o efeito de sugestão social - ou de ilusionismo social, segundo a expressão de Accardo (1983) - potencializado pelas práticas desinteressadas é tanto maior quanto maior for o poder de sugestão dos agentes que as realizam, isto é, quanto maior for o capital simbólico personificado pelo agente "desinteressado". Isso quer dizer que a taxa de câmbio simbólica entre os pares "distância respeitosa/desinteresse" e "familiaridade/desinteresse" é favorável ao primeiro, isto é, os necrológios permitem constatar que o poder simbólico no interior do magistério tende a acumular-se no primeiro par. A lei de retorno do capital simbólico, que faz com que o capital simbólico se incorpore tendencialmente no capital simbólico (cf. Bourdieu, 1989, p. |45), manifestação da lei mais geral de acumulação dos capitais, comanda a distribuição desigual, no campo do magistério e alhures, dos signos de fama, distinção e poder.

Assim como à familiaridade, a distância respeitosa também opõe-se à operosidade (perseverante, dedicado, prestante), signo de reconhecimento que trai uma condição modesta e os esforços, muitas vezes inúteis, para superá-la. A oposição entre a distância respeitosa e a operosidade é uma outra forma possível da oposição que se estabelece entre o dom e a hereditariedade (sinal de "nobreza" dos bem-nascidos), por um lado, e o mérito pelo trabalho (sinal "plebeu" dos que tentam pelo esforço compensar as carências materiais e culturais de nascimento), por outro. Os adjetivos que expressam as qualidades mais pessoais também seguem a lógica das dicotomias. Os agentes mais bem situados no magistério recebem adjetivos que sugerem as atividades viris e públicas de liderança (ardoroso, veemente, entusiasta: pólo masculino), opostos aos adjetivos que sugerem o recato e a placidez do mundo privado (amável, sincero, bondoso: pólo feminino), reservados aos agentes situados em posições discretas. Menos uma oposição e mais uma assimetria é a que se estabelece entre a abundância de adjetivos reservados aos agentes masculinos e a parcimônia dos adjetivos destinados a qualificar os agentes femininos. Essa assimetria estabelece-se quer entre os agentes masculinos e femininos de carreiras modestas (este, o caso mais comum), quer entre os agentes masculinos e femininos de carreiras de realce e projeção (caso numericamente mais raro).

\section{CONSIDERAÇÕES FINAIS}

Para apreender a lógica dos jogos simbólicos praticados pelos membros do magistério paulista nos anos 80 , procurou-se construir um estado do magistério oficial paulista como um "sistema estruturado das práticas e das expressões dos agentes" (Bourdieu, 1992, p. 8I), ou seja, como uma configuração possível, uma possibilidade construída a partir de duas opções imbricadas: I. dos valores em estado prático, ou seja, incorporados imperceptivelmente pela simples imersão e socialização do agente no campo, valores que não precisam ser propositalmente enunciados nem muito menos codificados para os fins da 
transmissão. Valores adquiridos, como diz Bourdieu, "sem regras nem critérios explícitos", quais sejam, os acionados pelos professores nas situações práticas, os modelos recomendados de comportamento profissional, os padrões de julgamento moral e os qualificativos utilizados para classificar e ser classificado; e 2. das estratégias pelas quais os professores paulistas lançam mão para distinguir-se tanto uns dos outros quanto em relação aos demais grupos profissionais.

A apreensão dos jogos simbólicos praticados pelo professorado na época contemporânea permite lançar luz nas reações dos professores às estratégias de relegação que Ihes foram impostas pelos demais grupos sociais, sobretudo nos anos 80 , uma década de forte "arrocho" salarial e de queda-livre da auto-estima e da imagem profissional da categoria, bem como nos mecanismos utilizados pelos professores para adaptarem-se, num processo de "cumplicidade objetiva" (Bourdieu, 1992), a uma profissão socialmente reconhecida como de baixo retorno tanto simbólico quanto material. No limite, o que se busca esclarecer é a inserção da prática dos professores nos processos de reprodução das estruturas sociais, inserção que se dá sempre, para usar as classificações que foram moda num passado recente da análise educacional, num misto não eliminável de reprodução (forte) e resistência (fraca), explicável à luz da tríplice dominação a que está sujeita a categoria, ao contrário do que em geral é afirmado nas descrições populistas do movimento dos professores, mais inclinadas a ressaltar as virtudes transformadoras da prática educativa escolar.

Finalmente, os termos e expressões utilizados para identificar os agentes mortos nos necrológios analisados possivelmente compõem o que Bourdieu chama de "ficção bem fundada", ou seja, os adjetivos, que são expressões dos critérios de valoração do magistério, as prescrições de práticas tidas como modelares, os qualificativos evocados para dar conta dos postos altos e dos postos baixos, das carreiras gloriosas e das carreiras discretas, enfim, os valores em estado prático são realidades sociais que não têm outro fundamento no real senão o fato de serem construções sociais, e, como tais, são realidades que extraem todo o seu poder de nomeação do fato de serem coletivamente reconhecidas. "Quando se trata do mundo social", escreve Bourdieu (1993, p.33), "as palavras fazem as coisas, pois elas fazem o consenso sobre a existência e o sentido das coisas, o senso comum, a doxa aceita por todos como evidente".

\section{REFERÊNCIAS BIBLIOGRÁFICAS}

ACCARDO, A. Initiation à la sociologie de l'illusionisme social: lire Bourdieu. Bordeaux: Le Mascaret, 1983

BOURDIEU, P. A Dominação masculina. Educação \& Realidade, v.20, n.2, p. I33-84, 1995.

Espaço social e gênese das classes. O poder simbólico. Lisboa: Difel; Rio de Janeiro: Bertrand Brasil, 1989, p. 133-62. 
Méditations pascaliennes. Paris: Seuil, 1997.

À propos de la famille comme catégorie réalisée. Actes de la Recherche en Sciences Sociales. n. 100, p. 32-6, 1993. 1992.

Réponses. por une antropologie réflexive (avec Loïc Wacquant). Paris: Seuil,

BOURDIEU, P., PASSERON J.-C. Language and relationship to language in the teaching situation. In: BOURDIEU, P. et al. Academic discourse: linguistic misunderstanding and professorial power. Stanford, CA: Stanford University Press, 1994. p. 2-34.

BOURDIEU, P., SAINT-MARTIN, M. Gostos de classe e estilos de vida. In: ORTIZ, R. (org.). Pierre Bourdieu, sociologia. São Paulo: Ática, 1983. p.82-121. (Col. Grandes cientistas sociais)

MICELI, S. Poder, sexo e letras na República Velha: estudo clínico dos anatolianos. São Paulo: Perspectiva, 1977. 
